carotid stiffness determining may be useful additional tools for cardiovascular risk evaluating in this pts.

Disclosure of Interest: None declared

DOI: 10.1136/annrheumdis-2017-eular.5343

\section{AB0353 ASSOCIATED FACTORS FOR FALLS AND FEAR OF FALLING IN AMBULATORY PATIENTS WITH RHEUMATOID ARTHRITIS: A COMPARATIVE STUDY WITH HEALTHY SUBJECTS}

A. Yesim ${ }^{1}$, Y. Ulus ${ }^{1}$, T. Berna ${ }^{1}$, L. Tomak ${ }^{2}$, Y. Zahiroglu ${ }^{1}$, A. Bilgici ${ }^{1}$, O. Kuru $^{1}$. ${ }^{1}$ Department of Physical Therapy and Rehabilitation, Faculty of Medicine; ${ }^{2}$ Department of Biostatistics, Faculty of Medicine, Ondokuzmayıs University, Samsun, Turkey

Background: Rheumatoid arthritis (RA) is a chronic disease that affects the bone and joints. Patients with RA migth be considered to be at increased risk of falls and FOF for a variety of reasons, including the presence of muscle weakness and stiff or painful joints of the lower extremities resulting in impaired physical activity, mobility, balance, and postural stability $(1,2)$.

Objectives: The aim of the present study was to compare fall history and fear of falling (FOF) in patients with RA with healthy controls, and to investigate their relationships between the demographic features, severity of pain, disability, disease activity, walking velocity, balance and emotional status in patients with RA.

Methods: One hundred-twenty patients with RA and 60 healthy volunteers were included in the study. Their fall history (yes, no) and the number of falls within the last year were questioned. FOF by presence of FOF (yes/no) and by Falls Efficacy Scale-International-I (FES-I), walking time by 10 Meter Walk Test (10MWT), balance by One-Leg Stand Test (OLST) and Berg Balance Scale (BBS), emotional status by Beck Depression Inventory (BDI) and Beck Anxiety Inventory (BAI) were performed in both groups. Pain severity and patient global assessment (PGA) by Visual Analogue Scale (VAS), disability by the Health Assessment Questionnaire (HAQ), disease activity by Disease Activity Score-28 (DAS-28) were evaluated in patients with RA.

Results: There was no statistically difference between the RA patients and controls in terms of presence of fall history while presence of FOF and FESI scores were significantly high in patients. PGA, 10MWT, pain VAS, HAQ, FES-I, BAI and BDI scores were significantly high, BBS score and OLST were significantly low fallers when compared to the non-fallers in the patients $(p<0.05)$. In the patient group, FES-I score was significantly correlated with pain VAS, PGA, DAS-28, HAQ, BAI, BDI, 10MWT positively, and BBS, OLST negatively $(p<0.05)$. In regression analysis; the number of falls, $H A Q, B B S$ and $B D I$ scores were detected to be the apparent independent risk factors affecting variations in FES-I scores $(p<0.001)$.

Conclusions: According to the results of our study, ambulatory patients with RA have increased FOF, disturbed balance, increased walking time and impaired emotional status compared with controls. On the other hand; walking time, pain severity, disability, scores of emotional status and PGA were higher, while the balance scores were lower in the RA patients with fallers. There were relationships between FOF and increased pain, high disease activity and anxiety level, impaired PGA, increased walking time but the most important factors associated with FOF were impaired balance, increased disability and depression, and number of falls in RA patients. Strategies for preventing falls, maintaining balance, improving emotional status and againts FOF are of the utmost importance in patients with RA.

\section{References:}

[1] Armstrong C, Swarbrick CM, Pye SR, O'Neill TW. Occurrence and risk factors for falls in rheumatoid arthritis. Ann Rheum Dis.2005;64:1602-4.

[2] Jamison M, Neuberger GB, Miller PA. Correlates of falls and fear of falling among adults with rheumatoid arthritis. Arthritis Rheum. 2003;49:673-80.

Disclosure of Interest: None declared

DOI: 10.1136/annrheumdis-2017-eular.2888

\section{AB0354 PREVALENCE OF SIGNS OF CONNECTIVE TISSUE DYSPLASIA IN PATIENTS WITH RHEUMATOID ARTHRITIS AND CHARACTERISTICS OF THE COURSE OF COMBINED PATHOLOGY}

R. Demidov, S. Lapshina, L. Myasoutova. Kazan State Medical University, Kazan, Russian Federation

Background: Connective tissue dysplasia (CTD) has a common pathogenesis with rheumatoid arthritis (RA). Question of peculiarities in such combination remains little known.

Objectives: To analyze the peculiarities of RA in patients with signs of CTD.

Methods: Among the 107 patients with RA, seen in the rheumatology departments in Kazan city, 18 (16.8\%) patients ( 15 women and 3 men, mean age $47,9 \pm 12,89$ years) with reliable signs of CTD were selected, identified clinically and the analysis of their documentation was performed. By DAS28 low RA activity was detected in $1(5.6 \%)$ patients, average - $13(72.2 \%)$, high - $4(22.2 \%)$. The clinical-laboratory and instrumental methods of diagnosis, standardized and independently developed questionnaire for the presence of CTD in selected group of patientswere used
Results: The most frequently following signs of CTD syndrome - vegetativevascular dystonia - $14(77.7 \%)$, myopia - in $9(50 \%)$, mitral valve prolapse- in 6 $(33.3 \%)$, small heart abnormalities - in $8(44.4 \%)$, flat feet - $6(33.3 \%)$, scoliosis in $5(27.7 \%)$, hyperkyphosis - in $2(11.1 \%)$, hypermobility of joints - in $2(111 \%)$, anomaly of kidney structure- in $2(11.1 \%)$, rhythm and conduction disturbancesin $7(38.8 \%)$. Osteoporosis was observed in $11(61.1 \%)$ patients.

We select two group of patients: the first $(n=9)$ from 1 to 5 CTD signes and the second $(n=9)-$ from 6 to 9 dysplasia symptoms. In the second group RA activity by DAS28 was significantly $(p \leq 0.05)$ higher $(4.52 \pm 1,20)$ than in the first (DAS28 $=3.95 \pm 0.81$. Obtained differences in RA activity, depending on the availability of myopia (DAS28 $=4,68 \pm 0,87$ ) or its absence (DAS28 $=3,78 \pm 1,06$ ); flatfoot (DAS28 $=4,53 \pm 1,05$ ) or its absence (DAS28 $=4,04 \pm 1,02$ ) were evaluated. A significant $(p \leq 0.05)$ difference was found in patients with osteoporosis, the availability for activity (DAS28 $=4.68 \pm 0.97)$, pain intensity VAS $(1,44 \mathrm{sm} \pm 6.90)$, compared with normal bone density tissue (DAS28 $=3,36 \pm 0,36$, pain VAS $=5,83 \pm 2,22 \mathrm{~cm}$ ).

Conclusions: Among patients with RA CTD signes occur more frequently than in the population (16.8\% versus $10 \%)$. The most frequently detected are myopia, vegetative-vascular dystonia, cardiac diseases, osteoporosis. Patients with signs of dysplasia had a trend towards a higher activity of RA.

Disclosure of Interest: None declared

DOI: 10.1136/annrheumdis-2017-eular.3968

\section{AB0355 MUSCLE POWER AND FALL RISK IN RHEUMATOID ARTHRITIS}

R. Dietzel, D. Felsenberg, G. Armbrecht. Centre of Muscle and Bone Research, Charite, Berlin, Germany

Background: One of the serious consequences of aging is the gradual loss of muscle function, a phenomenon called sarcopenia. Skeletal muscle power refers to the ability to generate high-velocity movements and current evidence suggests that it declines earlier with advancing age [1] and is more strongly related to functional status than muscle force [2]. A decreased capacity for high-velocity movements in the legs has been linked to delayed responses in maintaining postural stability and thus with age-associated fall risk [3]. People with rheumatoid arthritis (RA) may be at high risk of falling due to disease-related impairments such as pain, joint deformity, muscle weakness, altered gait and decline in postural stability.

Objectives: As role of muscle power in fall-risk assessment of RA patients has not been investigated, so far, the aim of the present study was to determine the association between muscle power, muscle force, functional performance and falls in the last 12 months in RA patients.

Methods: 98 subjects with RA older than 60 years from a cross-sectional study on the prevalence of corticoid-induced osteoporosis in Germany (PSIO-D Berlin) and 98 age-matched controls without inflammatory disease, randomly chosen from a cross-sectional study collecting reference values for body composition, were analyzed in this case-control study. Muscle function was determined by muscle power per body mass in vertical countermovement jumps $\left(2 L_{J} P_{\text {rel }}\right)$ on a force plate, the chair rise test (CRT), gait speed, grip strength and the Short Physical Performance Battery. Differences in muscle function measures between the RA group and the healthy reference were derived separately by sex with Student-T-test or Mann-Whitney-U-test. Using logistic regression adjusted for age and sex the association between muscle function and falls was determined.

Results: In bivariate analysis RA patients showed significantly weaker performance in all muscle function tests compared to controls in both sexes. Applying logistic regression, age (OR 1.10, 95\% $>\mathrm{Cl} 1.00-1.24)$ and female sex (OR 5.99, $95 \%>\mathrm{Cl} 1.25-28.57$ ) were significantly associated with retrospective falls in RA subjects but not in controls. Gait speed (OR $0.09,95 \%>\mathrm{Cl} 0.01-0.88$ ) remained a significant correlate for falls independent of age and sex in RA patients. In controls only the CRT (OR 1.13, 95\%>Cl 1.02-1.26) could differentiate individuals who had past fall events in the age and sex adjusted model. No association was found for the $2 \mathrm{LJP}_{\text {rel }}$ and retrospective falls.

Conclusions: The results of the present study could not confirm an association between fall risk and muscle power in RA patients, but they highlight the importance of monitoring neuromuscular function such as gait speed, in order to prevent falls and consequently to prevent fractures, contributing to a better prognosis of rheumatic disease.

\section{References:}

[1] Lauretani, F., et al., Age-associated changes in skeletal muscles and their effect on mobility: an operational diagnosis of sarcopenia. J Appl Physiol, 2003. 95(5): p. 1851-60.

[2] Bean, J.F., et al., A comparison of leg power and leg strength within the InCHIANTI study: which influences mobility more? J Gerontol A Biol Sci Med Sci, 2003. 58(8): p. 728-33.

[3] Pereira, A., et al., Effects of high-speed power training on functional capacity and muscle performance in older women. Exp Gerontol, 2012. 47(3): p. 250-5. Disclosure of Interest: None declared DOI: 10.1136/annrheumdis-2017-eular.1957 